\title{
Exploratory laparoscopy combined with pathological examination in the diagnosis of obscure gastrointestinal bleeding in a child: a case report
}

\author{
Jiande Chen ${ }^{1+}$, Bin Zhang ${ }^{2 \dagger}$, Zhilong Yan ${ }^{3}$, Huaying Zhao ${ }^{3}$, Kaihua Yang ${ }^{2}$, Yong Yin ${ }^{1 *}$ and Lirong Jiang ${ }^{2^{*}}$
}

\begin{abstract}
Background: The diagnosis of obscure gastrointestinal bleeding (OGIB) which is defined as bleeding of unknown origin of the small bowel by routine evaluation in childhood is a challenge.

Case presentation: Here we report a one-year-old Chinese girl who was suspected with idiopathic pulmonary haemosiderosis (IPH) and referred to our department for further diagnosis. Finally she was diagnosed with vascular malformations (VM) by exploratory laparoscopy combined with pathological examination.

Conclusions: Children OGIB could be easily misdiagnosed in the beginning, and OGIB children with active ongoing bleeding may benefit from proceeding directly to exploratory laparoscopy, followed by pathological confirmation of the diagnosis.
\end{abstract}

Keywords: Iron-deficiency anemia, Melena, Vascular malformations

\section{Background}

Obscure gastrointestinal bleeding (OGIB) is defined as bleeding of unknown origin that persists or recurs after bidirectional endoscopy and radiologic evaluation of the small bowel [1]. It could be categorized into obscure overt and obscure occult bleeding based on the presence or absence of clinically evident bleeding [2]. Causes of OGIB may potentially include lesions that are overlooked in the esophagus, stomach, and colon during initial workup or lesions in the small intestine that are difficult to visualize with conventional endoscopy and radiologic imaging [1]. After negative endoscopy and colonoscopy, performing small bowel endoscopic investigation by capsule endoscopy (CE) and balloon-assisted enteroscopy (BAE) has a very good diagnostic yield [3].

\footnotetext{
* Correspondence: yinyong9999@163.com; jiangl_rong@aliyun.com † Jiande Chen and Bin Zhang contributed equally to this work.

'Department of Respiratory Medicine, Shanghai Children's Medical Center Affiliated to Shanghai Jiao Tong University School of Medicine, No.1678 Dongfang Road, Pudong 200127, Shanghai, China

2Department of Gastroenterology, Shanghai Children's Medical Center Affiliated to Shanghai Jiao Tong University School of Medicine, No.1678 Dongfang Road, Pudong 200127, Shanghai, China

Full list of author information is available at the end of the article
}

Intraoperative enteroscopy is currently reserved as a last option, for when other measures cannot identify a bleeding source in selected patients.

This paper presents an unusual case study of a one-year-old girl who presented with OGIB, the subsequent diagnostic challenges encountered and how these were addressed.

\section{Case presentation}

A nine-month-old Chinese girl presented with one-week history of pallor at a referral hospital where she received a

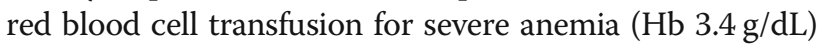
and started to treat for iron-deficiency anemia (IDA) after microcytosis (mean corpuscular volume $74.6 \mathrm{fl}$ ), hypochromia (mean cell Hb $21.5 \mathrm{pg}$ ), and low serum iron concentration $(1.28 \mathrm{umol} / \mathrm{L})$ were confirmed. On discharge after 1 week of treatment, anemia was corrected $(\mathrm{Hb} 12.4$ $\mathrm{g} / \mathrm{dL}$ ). However, recurrent anemia was observed over a six-month period, even another red blood cell transfusion was given in this period. Positive fecal occult blood test results were intermittent. A chest computed tomography (CT) scan showed the increase of patch density in the left 
lower lobe (Fig. 1a) and right upper lobe (Fig. 1b) of the lung. Although she had no history of repetitive haemoptysis, chronic cough and dyspnoea, idiopathic pulmonary haemosiderosis (IPH) was entertained and the IDA therapy was discontinued.

Patient was referred to our hospital for further management. Flexible bronchoscopy was performed, but bronchoalveolar lavage examination of blood-stained fluid and hemosiderin-laden macrophages from involved areas was negative. Review of the chest CT scan showed no extensive ground glass opacities and reticular shadows. Therefore, diffuse alveolar haemorrhage was ruled out. Review of the patient's history found an episode of intermittent melena 1 month after the IDA treatment, and that was considered to be the side effect of the drug by the outpatient doctor. No related family genetic history. Physical exam demonstrated a girl of normal appearance consistent with her ethnicity except pallor. The diagnostic approach for gastrointestinal bleeding was started. However, the patient underwent both upper and lower endoscopy with negative findings in all of the endoscopic examinations. Plain and enhanced CT of abdomen and the technetium-99 m-labeled red blood cell scans were performed. Again, they were all negative. Her symptoms persisted and one red blood cell transfusion was needed each week.

The department of general surgery was involved in the management and a decision to do surgical exploration with laparoscopy was taken. A $3 \mathrm{~cm}$ lesion with dense blistered protrusions on the surface was found within the wall of jejunum (Fig. 2), acting as a lead point, so a jejunal segment was resected and an end to end jejunojejunostomy was performed. Pathological examination indicated a vascular malformations (VM) (Fig. 3). Postoperative period was uneventful and she was discharged

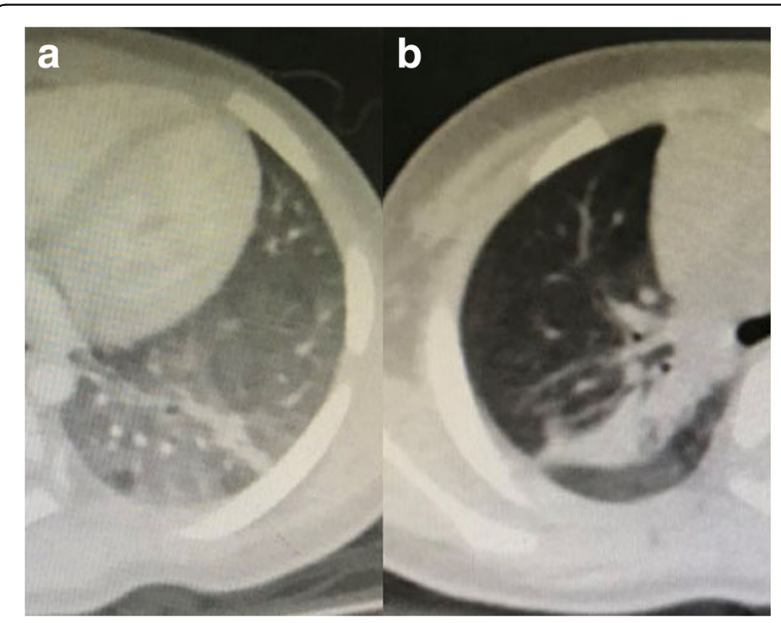

Fig. 1 Chest CT. Increased patch density in the left lower lobe (a) and the right upper lobe (b) of the lung

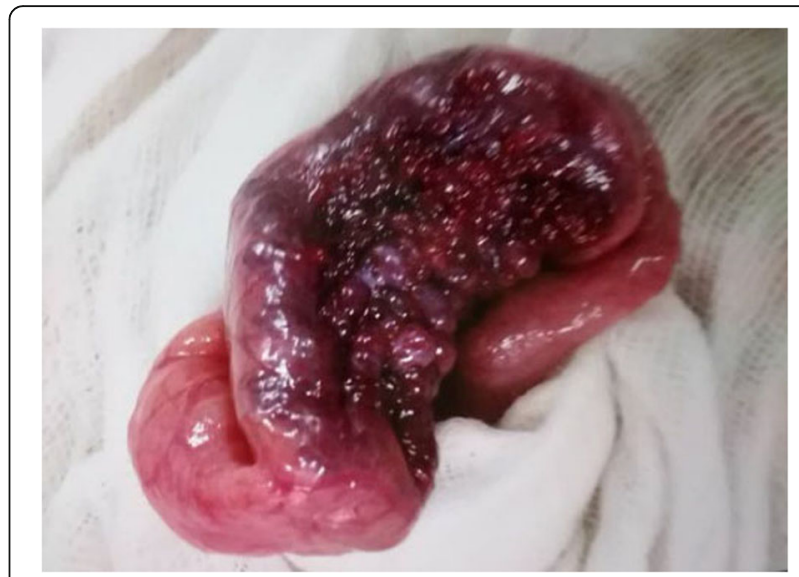

Fig. 2 Lesion within the wall of jejunum. A $3 \mathrm{~cm}$ lesion with dense blistered protrusions on the surface within the wall of jejunum

home with no complications. There was no recurrence during follow-ups.

\section{Discussion and conclusions}

OGIB from VM in this case affected the delay in diagnosis because of its rarity and limitations in the diagnostic approach in pediatric patients.

Massive gastrointestinal haemorrhage in a child due to $\mathrm{VM}$ of the jejunum is very uncommon [4]. To our knowledge this is the second case of an acute gastrointestinal haemorrhage in a child due to VM of the jejunum. Most VM cases may lay a false trail for the clinician because of accompanied IDA with no gastrointestinal symptoms at the initial time [5]. In our case, IDA combined with asymptomatic pulmonary infection misled the diagnosis as IPH. The clinical conditions of our case are reported for the first time.

Syndromes such as the Klippel-Trenaunay syndrome and the blue rubber blebnevus syndrome usually encompass $\mathrm{VM}$ as a skin manifestation, so the possibility of visceral lesion may be suspected. In this case, however, the malformations were a unique manifestation without any associated syndrome, which increased the difficulty of diagnosis.

Angiography may detect OGIB lesions and also offers a therapeutic option with embolization if a bleeding lesion is identified. In OGIB patients, the bleeding rate may be slow or intermittent, thereby not allowing identification by either angiography or bleeding scan [6]. A small case series also suggests that the overall yield of provocative angiography is low [7].

$\mathrm{CE}$ is currently the preferred test for the initial investigation in patients with OGIB due to its high diagnostic yield [1]. However, this technology requires precision instruments and skilled endoscopic images interpreters. In addition, the increase of the cost-effectiveness, imprecise localization, the risk of capsule retention and a lack of 


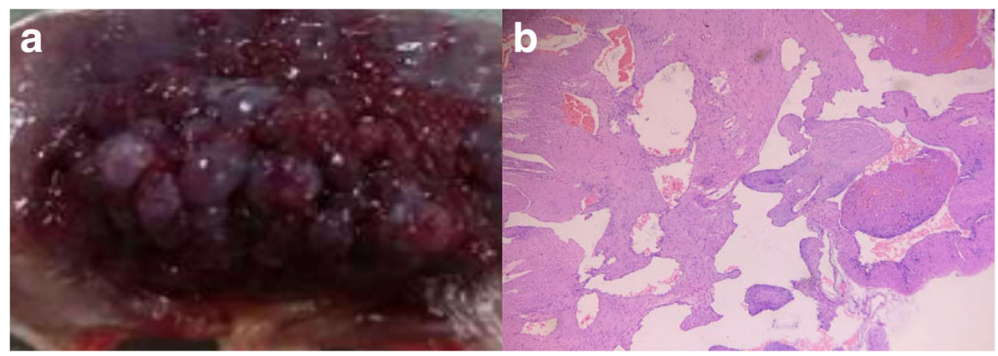

Fig. 3 Gross view and microscopic features of intestinal wall VM. Macroscopically, there was a lesion with dense blistered protrusions on the surface within the intestinal wall (a). On microscopy, abnormal collections of dilated vascular structures of variable sizes were observed in the lesion (b, original magnification $\times 10$ )

therapeutic capability also restrict the wide application of $\mathrm{CE}$ among children patients, particularly in acute cases.

OGIB was a common indication for small bowel endoscopy. The development of BAE represents a decisive breakthrough in the diagnosis and management of small bowel diseases. The overall diagnostic yield of BAE was about $70 \%[8,9]$. The approach of CE followed by BAE might show a diagnostic yield over 90\% [10]. However, this technology has not been widely used in children's hospitals for concerns regarding safety, design of instruments, training, availability, and a lack of knowledge about its use and relative indications.

The safety and effectiveness of using laparoscopy as the diagnostic and therapeutic tool for OGIB in children have been well established by pediatric literature [11-14]. In the cases of difficult-to-manage or acute bleeding, we may directly resort to laparoscopy for difficult-to-access lesions. Pathological examination should be performed to make a definite diagnosis after lesions resection.

Our experience of successful management of this case suggested that children OGIB combined with asymptomatic pulmonary infection could be easily misdiagnosed as IPH in the beginning, and OGIB children with active ongoing bleeding may benefit from proceeding directly to exploratory laparoscopy, followed by pathological confirmation of the diagnosis.

\section{Abbreviations}

BAE: Balloon-assisted enteroscopy; CE: Capsule endoscopy; CT: Computed tomography; IDA: Iron-deficiency anemia; IPH: Idiopathic pulmonary haemosiderosis; OGIB: Obscure gastrointestinal bleeding; VM: Vascular malformations

\section{Acknowledgments}

We thank the patient and her family. We also thank pathology department, radiology department, rheumatism department, hematology-oncology department and other departments of Shanghai Children's Medical Center Affiliated to Shanghai Jiao Tong University School of Medicine for their assistance.

\section{Funding}

Not applicable.

\section{Availability of data and materials}

The data and materials used and/or analysed during the current study were presented within the manuscript.

\section{Authors' contributions}

$J C$ and BZ interpreted the results for the case report, drafted, wrote and revised the report, and provided important intellectual review. $\mathrm{ZY}$ and $\mathrm{HZ}$ carried out the surgical exploration with laparoscopy and helped to draft the manuscript. KY collected the data from our hospital work system and critically reviewed the manuscript. YY and $\mathrm{L}$ conceived of the study, and participated in its design and coordination and helped to review the manuscript. All authors read and approved the final manuscript.

Ethics approval and consent to participate

This study was approved by the Ethics Committee of Shanghai Children's Medical Center Affiliated to Shanghai Jiao Tong University School of Medicine and was conducted in accordance with the Declaration of Helsinki.

\section{Consent for publication}

Written informed consent was obtained from the parent for the publication of this case report.

\section{Competing interests}

The authors declare that they have no competing interests.

\section{Publisher's Note}

Springer Nature remains neutral with regard to jurisdictional claims in published maps and institutional affiliations.

\section{Author details}

${ }^{1}$ Department of Respiratory Medicine, Shanghai Children's Medical Center Affiliated to Shanghai Jiao Tong University School of Medicine, No.1678 Dongfang Road, Pudong 200127, Shanghai, China. ${ }^{2}$ Department of Gastroenterology, Shanghai Children's Medical Center Affiliated to Shanghai Jiao Tong University School of Medicine, No.1678 Dongfang Road, Pudong 200127, Shanghai, China. ${ }^{3}$ Department of General Surgery, Shanghai Children's Medical Center Affiliated to Shanghai Jiao Tong University School of Medicine, No.1678 Dongfang Road, Pudong 200127, Shanghai, China.

Received: 11 April 2018 Accepted: 12 November 2018

Published online: 27 November 2018

\section{References}

1. Raju GS, Gerson L, Das A, Lewis B. American gastroenterological association (AGA) institute technical review on obscure gastrointestinal bleeding. Gastroenterology. 2007;133(5):1697-717.

2. American Gastroenterological Association medical position statement: evaluation and management of occult and obscure gastrointestinal bleeding. Gastroenterology. 2000;118(1):197-201.

3. Romano C, Oliva S, Martellossi S, Miele E, Arrigo S, Graziani MG, Cardile S, Gaiani F, de'Angelis GL, Torroni F. Pediatric gastrointestinal bleeding: perspectives from the Italian Society of Pediatric Gastroenterology. World J Gastroenterol. 2017;23(8):1328-37.

4. Kimpton JA, Bowen JC, Craigie RJ. Paediatric angiodysplasia of the jejunum: a case report and review of the literature. Scott Med J. 2012;57(4):247. 
5. Kim SH, Cho YH, Kim HY. Vascular malformations of the small intestine manifesting as chronic anemia: two pediatric cases managed by single-site umbilical laparoscopic surgery. Int J Surg Case Rep. 2017;31:233-6.

6. Rantis PCJ, Harford FJ, Wagner RH, Henkin RE. Technetium-labelled red blood cell scintigraphy: is it useful in acute lower gastrointestinal bleeding? Int J Color Dis. 1995;10(4):210-5.

7. Bloomfeld RS, Smith TP, Schneider AM, Rockey DC. Provocative angiography in patients with gastrointestinal hemorrhage of obscure origin. Am J Gastroenterol. 2000;95(10):2807-12.

8. Hong SN, Kim ER, Ye BD, Jang HJ, Jeon SR, Park SJ, Im JP, Kim JH, Choi CH, Choi $\mathrm{H}$, et al. Indications, diagnostic yield, and complication rate of balloon-assisted enteroscopy (BAE) during the first decade of its use in Korea. Dig Endosc. 2016; 28(4):443-49.

9. Ma JJ, Wang $Y, X u X M$, Su JW, Jiang WY, Jiang JX, Lin L, Zhang DQ, Ding J, Chen $\mathrm{L}$, et al. Capsule endoscopy and single-balloon enteroscopy in small bowel diseases: competing or complementary? World J Gastroenterol. 2016; 22(48):10625-30.

10. Oliva S, Pennazio M, Cohen SA, Aloi M, Barabino A, Hassan C, Pession A, Lima M, Frediani S, Di Nardo G. Capsule endoscopy followed by single balloon enteroscopy in children with obscure gastrointestinal bleeding: a combined approach. Dig Liver Dis : official journal of the Italian Society of Gastroenterology and the Italian Association for the Study of the Liver. 2015;47(2):125-30.

11. Lee KH, Yeung CK, Tam YH, Ng WT, Yip KF. Laparascopy for definitive diagnosis and treatment of gastrointestinal bleeding of obscure origin in children. J Pediatr Surg. 2000;35(9):1291-3.

12. Pal K, El Shafei H, Al Buainain H, Mitra DK. Successful laparoscopic treatment of hemorrhage from ileal duplication cyst in a 10-year-old Saudi boy. J Laparoendosc Adv Surg Tech Part A. 2010;20(1):99-101.

13. Loh DL, Munro FD. The role of laparoscopy in the management of lower gastro-intestinal bleeding. Pediatr Surg Int. 2003;19(4):266-7.

14. Craigie RJ, Forrest N, Nanthakumaran S, Mahomed AA. Laparoscopy in diagnosis and management of Meckel's diverticulum. J Laparoendosc Adv Surg Tech Part A. 2006;16(1):70-3.

Ready to submit your research? Choose BMC and benefit from:

- fast, convenient online submission

- thorough peer review by experienced researchers in your field

- rapid publication on acceptance

- support for research data, including large and complex data types

- gold Open Access which fosters wider collaboration and increased citations

- maximum visibility for your research: over $100 \mathrm{M}$ website views per year

At $\mathrm{BMC}$, research is always in progress.

Learn more biomedcentral.com/submissions 